\title{
Nanoparticle Synthesis and Cytotoxicity of Kaempferia pandurata Roxb. Extract to the Growth of MDA-MB-231 Breast Cancer Cell Line
}

\author{
Risya Amelia Rahmawanti' , Fadilah Fadilah ${ }^{2, *}$, Brenda Cristie Edina', Lowilius Wiyono' ${ }^{1}$, Rafika Indah Paramita ${ }^{2}$
}

Risya Amelia Rahmawanti', Fadilah Fadilah ${ }^{2,3, *}$, Brenda Cristie Edina', Lowilius Wiyono', Rafika Indah Paramita ${ }^{2}$

'Undergraduate Medical Student, Faculty of Medicine University of Indonesia, Jalan Salemba Raya No.6, Jakarta Pusat, 10430, INDONESIA.

${ }^{2}$ Department of Medical Chemistry, Faculty of Medicine University of Indonesia, Jalan Salemba Raya No.6, Jakarta Pusat, 10430, INDONESIA.

${ }^{3}$ Drug Development Research Center - IMERI, Faculty of Medicine University of Indonesia, INDONESIA.

\section{Correspondence}

\section{Fadilah Fadilah}

Department of Medical Chemistry, Faculty of Medicine University of Indonesia, Jalan Salemba Raya No.6, Jakarta Pusat, 10430, INDONESIA

E-mail: fadilah81@gmail.com

History

- Submission Date: 02-09-2019;

- Review completed: 14-10-2019;

- Accepted Date: 21-10-2019.

DOI : 10.5530/pj.2020.12.17

Article Available online http://www.phcogj.com/v12/i1

Copyright

(C) 2020 Phcogj.Com. This is an open access article distributed under the terms of the Creative Commons Attribution 4.0 International license.

\begin{abstract}
Breast cancer is the most common cancer worldwide and in Indonesia. Kaempferia pandurata Roxb. is a herbal plant from South-East Asia which is known for its ability to inhibit the growth of Estrogen Receptor (ER) + breast cancer cell line from the former study. However, its effect on ER- breast cancer cell lines had not been studied. Therefore, we want to examine the cytotoxicity effect of $K$. pandurata Roxb. on ER- breast cancer cell line (MDA-MB-231). Nanoparticle is a form of preparation that optimizes the activity of any compound to the targeted cell. Therefore, it is expected that it can increase the effectivity of anticancer in Kaempferia pandurata Roxb. In this study, the rhizome of $K$. pandurata Roxb. trituration was dried and extracted with $n$-hexane solvent. Nanoparticle of $K$. pandurata Roxb. was synthesized with $\mathrm{CaCl} 2$, chitosan, and alginate by stirring with a magnetic stirrer, adjusting $\mathrm{pH}$, and centrifugation. Then, nanoparticle was analized by UVNIS spectrofotometry and transmission electron microscopy (TEM). The cytotoxicity of $K$. pandurata Roxb. extract and nanoparticle were examined with MTT assay. The result of this test is data of inhibition percentage and $\mathrm{IC}_{50}$ value. The result showed that $n$-hexane extract of $K$. pandurata Roxb. is synthesized into nanoparticle form with $99,43 \%$ yield percentage (entrapment value). Anticancer activity of $\mathrm{n}$-hexane extract and nanoparticle of $K$. pandurata Roxb. is moderate with $\mathrm{IC}_{50}$ value of the extract is $87,23 \mu \mathrm{g} / \mathrm{ml}$ and the nanoparticle is $24,23 \mu \mathrm{g} / \mathrm{ml}$. The nanoparticle's activity is better than the extract. $n$-Hexane extract and nanoparticle of $K$. pandurata Roxb. has cytotoxicity effects towards MDA-MB-231 cell line. Nanoparticle can increase the cytotoxicity effect of $K$. pandurata Roxb. extract because its hydrophobic feature and nanometer size.

Key words: Breast cancer, Kaempferia pandurata Roxb., MDA-MB-231 cells, Nanoparticle, Temu Kunci.
\end{abstract}

\section{INTRODUCTION}

Breast cancer is one of the most common cancer worldwide. The prevalence of breast cancer is the highest in the world with 6.9 million cases (GLOBOCAN 2018). ${ }^{1}$ In Indonesia, breast cancer is the most common cancer which incidence is $30,9 \%$ among women at all age. The prevalence of breast cancer in Indonesia is 160.653 cases. $^{2}$

Approximately $80 \%$ of all breast cancer cases are included in estrogen receptor positive (ER+) group and responsive to hormone therapy, while $15 \%$ are resistant. The latter are estrogen receptor negative (ER-) dan TNBC (ER-, PR-, dan HER2-).,3 MDAMB-231 breast cancer cell line is ER-. It tends to be malignant and has worse prognosis. ${ }^{5,6}$ The resistant case brought us to search a natural material that has bioactive compounds as an alternative of anticancer

Temu Kunci (Kaempferia pandurata Roxb.) is a herbal plant from South-East Asia and China. This plant contains flavonoid compound that has antifungal, anti-inflammatory, and anticancer function. ${ }^{7,8}$ The previous research reported that the extract of K. pandurata Roxb. can inhibit the growth of ER+ breast cancer cell line (e.g MCF7 dan T47D).$^{8-10}$ The effect of K. pandurata Roxb towards ER- breast cancer cell line is not much known. Flavonoid is the major compound of $\mathrm{K}$. pandurata Roxb. It is nonpolar. In order to increase the bioavailability of the compounds, we do the nanoparticle synthesis. ${ }^{11}$

Nanoparticle is a form of preparation that optimizes the activity of any compound to the targeted cell. It also increase the stability and lower the clearance because it is hidrofobic and has large surface area due to its nano size. ${ }^{11}$ Therefore, it is expected that it can increase the effectivity of anticancer in K. pandurata Roxb. ${ }^{12}$ This study use MTT assay to rate the cytotoxic effect from the extract and nanoparticle towards MDA-MB-231 cell. ${ }^{12}$ The purpose of this research is to conjugate extracts of $\mathrm{n}$-hexane K. pandurate Roxb. with alginate nanoparticles with a cross link chitosan medium to increase the effectiveness and efficiencies of breast cancer cell therapy. As well as studying the cytotoxic effects of nanoparticles chitosan cross-link chitosan medium chain integrated with N-heksan K. pandurata Roxb Extract in breast cancer cells MDAMB-231.

Cite this article: Rahmawanti RA, Fadilah F, Edina BC, Wiyono L, Paramita RI. Nanoparticle Synthesis and Cytotoxicity of Kaempferia pandurata Roxb. Extract to the Growth of MDAMB-231 Breast Cancer Cell Line. Pharmacog J. 2020;12(1):109-14. 


\section{MATERIALS AND METHOD}

This study is an experimental study and conducted at Department of Medical Chemistry - Faculty of Medicine University of Indonesia at Januari to April 2019. The free variables in this study are K. pandurata Roxb n-hexane extract and nanoparticle, the bound variable is MDA-MB-231 breast cancer cell, and the confounding variables are temperature and $\mathrm{pH}$.

\section{K. pandurata Roxb. preparation}

Kaempferia pandurata Roxb. was used in this study was obtained from Banjarnegara, West Java. MDA-MB-231 cell lines where obtained from Biobank Research FKUI-RSCM. The cell was supplemented with $10 \%$ fetal bovine serum (FBS) and incubated at $37^{\circ} \mathrm{C}$ with $4 \% \mathrm{CO}_{2}$. The viability of the cell is determined with trypan blue $0,1 \%$.

\section{Extraction}

One hundred grams of K. pandurata Roxb trituration was macerated for 48 hours, 3 times with $200 \mathrm{ml} \mathrm{n}$-hexane (each time) as the solvent in glass vessel. The glass was tightly closed and stirred once in a while. After that, it was filtered concentrated with rotary evaporator. The solids residue was then be dissolved again with $\mathrm{n}$-hexane solvent.

\section{Nanoparticle synthesis}

Nanoparticle synthesis of K.pandurata Roxb. n-hexane extract use three different test tube. The synthesis nanoparticles extract $\mathrm{N}$-hexane K. Pandurata are synthesized using $\mathrm{CaCl}_{2}$ and chitosan. The first solution, $50 \mathrm{mg} \mathrm{CaCl}$ dissolved in water $25 \mathrm{~mL}$ and continued 25 mg N-hexa extract of K. Pandurata inserted into $\mathrm{CaCl}_{2}$. was further homogenized by using a magnetic stirer for 2 hours. Second solution, dissolved sodium alginate as much as $200 \mathrm{mg}$ in $25 \mathrm{~mL}$ water and stir until dissolved and done $\mathrm{pH}$ arrangement by adding $\mathrm{HCl}$ until $\mathrm{pH}$ reaches 5.1. The next step of the first solution slowly in the second solution. Stir the stirring for 24 hours. The third solution uses Chitosan $50 \mathrm{mg}$ dissolved in $25 \mathrm{~mL}$ of $1 \%$ acetic acid. The solution was then mixed and the $\mathrm{pH}$ arrangement with $\mathrm{NaOH}$ to reach the $\mathrm{pH}$ value of 5.5. The solution was homogenized and added the Tween 80 as much as $0.31 \mathrm{G}$ and performed with a magnetig stirer for 2 hours in the temperature of $60{ }^{\circ} \mathrm{C}$. The third solution is slowly carried over at the first and second solution while stirring, stirring for 24 hours. The results were centrifuged as much as 2-3 times until filtrate nanoparticles were obtained. The obtained nanoparticles are analyzed using TEM and UV-Vis.
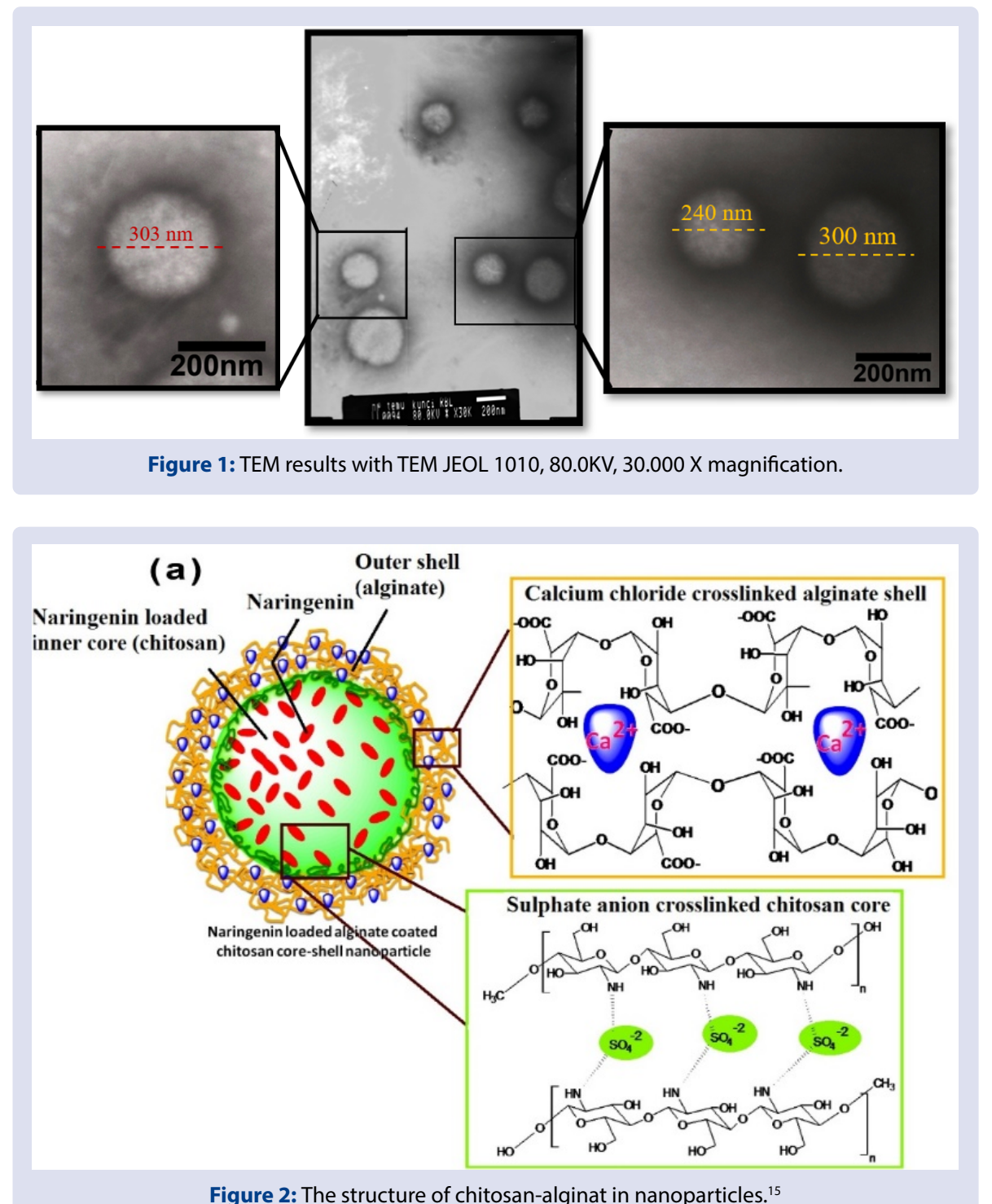


\section{Spectrophotometry UV/VIS}

Spectrophotometry UV/VIS is a simple and common method to quantitatively measure the absorbance of compounds in a solution. This spectrophotometry uses a UV light source and a visible light source with a certain range of wavelength. The principle is light emitted will cause the transition of electrons from low-energy orbits to highenergy orbits so that the detector can measure the absorption of light by these compounds. The concentration of the compound will be directly proportional to the absorbance value. This test is carried out in the Department of Medical Chemistry - Faculty of Medicine University of Indonesia. ${ }^{13}$

\section{Transmission electron microscopy (TEM)}

TEM test was carried out to determine the size and surface morphology of chitosan-alginate nanoparticles. The initial step in the processing of TEM is the sample preparation with $2 \%$ uranyl acetate in $\mathrm{ddH}_{2} \mathrm{O}$ (double distilled $\mathrm{H}_{2} \mathrm{O}$ ) at room temperature. Samples were dropped on carbon film paper called carbon coated copper grid and then dried at room temperature. After drying, the sample was analyzed by TEM. The TEM test was conducted at the Eijkman TEM and Histology Laboratory, Central Jakarta.

\section{Cytotoxicity test (MTT assay)}

The cytotoxicity activity of n-hexane extract and nanoparticles of K. pandurata Roxb. was measured by the MTT assay (3-

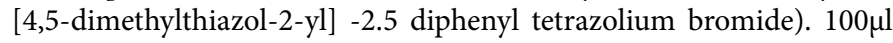
of MDA-MB-231 cell suspension with a density of $3 \times 104$ cells / 100 $\mu \mathrm{l}$ of media was distributed to a 96-well plate well and incubated for 24 hours. After that incubation, $100 \mu \mathrm{l}$ of the solution is put into the well in various levels of concentration 100; 50; $2512.5 ; 6.25$; and 3,125 $\mu \mathrm{g} /$ $\mathrm{mL}$ as much as $100 \mu \mathrm{L}$ (dilution) sentence structure using. The positive control is $100 \mu \mathrm{l}$ of different concentration of with doxorubicin as a postive control. The positive control was put into the well in various levels of concentration. For cell control, $100 \mu$ l of culture medium was added to $100 \mu \mathrm{l}$ of cell. The plate was incubated for 24 hours in an incubator with $5 \% \mathrm{CO}_{2}$ and $95 \% \mathrm{O}_{2}$ flow. After 24 hours, the plates were removed and $10 \mu \mathrm{l}$ of MTT solution was dissolved in $5 \mathrm{mg} / \mathrm{mL}$ Phosphate-Buffered Saline (PBS). After that the plates are re-incubated for 3-4 hours. The MTT reaction was stopped by adding $100 \mu \mathrm{l}$ SDS stopper reagent. The plates were allowed to stand for about 5 minutes and then wrapped in aluminum foil and incubated for 1 night at room temperature. The survived cells in plate will react with MTT solution and form a purple color (formazan). The test results are then read with an ELISA reader at a wavelength of $595 \mathrm{~nm}$.

\section{Data processing}

Absorbance value data from the MTT assay will be processed using Microsoft Excel into percentage inhibition, calculated by the formula:

$\%$ Inhibition $=\left(1-\frac{\text { Absorbance of sample }}{\text { Absorbance of control }}\right) \times 100 \%$

After obtaining the inhibition rate, the data is plotted into a linear regression graph. Through the graphical equation, IC50 is obtained from the anti- $\log X$ calculation $(y=50)$.

\section{RESULTS}

\section{Extraction of $K$. pandurata Roxb.}

The parameter to assess extract quality is the extract yield. The extract yield is the ratio between the extract obtained with the initial simplicia. The extract yield in this study was $13.25 \%$. It is obtained from the formula:
Extract yield $(\%)=\frac{\text { Extract mass that is obtained }(\text { grams })}{\text { Simplisia mass before extraction (grams) }} \times 100 \%$

\section{Spectrophotometry UV/VIS}

The spectrophotometry UV/VIS produces an absorbance graph of the concentration with the line equation $y=0.0054 \mathrm{x}-0.0122$. Through this line equation, it is obtained that the free concentration of the extract which is not captured by nanoparticles is $5.7 \mathrm{ppm}$. This concentration is used to calculate yield (\%) which is the percentage of nanoparticle capture. The yield (\%) in this study was $99.43 \%$. Yield (\%) is obtained from the formula:

Yield $(\%)=\frac{\text { initial concentration }(\mathrm{ppm})-\text { free concentration }(\mathrm{ppm})}{\text { initial concentration }(\mathrm{ppm})} \times 100 \%$

\section{Transmission electron microscopy (TEM)}

TEM test results describe the shape and size of nanoparticles of $\mathrm{K}$. pandurata Roxb n-hexane extract. The shape of nanoparticles are round like vesicles. The size of nanoparticles according to Figure 2 is $240-303$ $\mathrm{nm}$.

\section{MTT assay}

MTT assay produce the percentage inhibition of each sample group. In general the percentage inhibition of $\mathrm{n}$-hexane extract of K. pandurata Roxb., nanoparticle of K. pandurata Roxb. n-hexane extract, and doxorubicin showed a relationship that was directly proportional to its concentration (Table 1). The percentage inhibition increases with increasing concentration. At the same concentration, the order of percentage values of inhibition from highest to lowest was doxorubicin, nanoparticle of K. pandurata Roxb. n-hexane extract, and n-hexane extract of K. pandurata Roxb., for example at a concentration of 12.5, the percentage inhibition with high to low values for doxorubicin, nanoparticles of K. pandurata Roxb. n-hexane extract, and n-hexane extract of K. pandurata Roxb. were 72.5\%, 39.1\%, and 18.5\%.

A small $\mathrm{IC}_{50}$ value indicates high activity as an anticancer. Doxorubicin as a positive control had the smallest $\mathrm{IC}_{50}$ value, with an average of $1.66 \mu \mathrm{g} / \mathrm{ml}$. The average $\mathrm{IC}_{50}$ value of nanoparticle of $\mathrm{K}$. pandurata Roxb. $n$-hexane extract is lower than the average $\mathrm{IC}_{50}$ value of $n$-hexane extract of K. pandurata Roxb..

Tabel 1: Persentage inhibition of $n$-Hexane extract of K. pandurata Roxb., nanoparticle of K. pandurata Roxb. $n$-Hexane Extract, and Doxorubicin to MDA-MB-231 cells.

\begin{tabular}{cccc}
\hline \multirow{2}{*}{ Concentration } & \multicolumn{3}{c}{ Percentage Inhibition (\%) (Mean \pm S.D) } \\
\cline { 2 - 4 } & Extract & Nanoparticle & Doxorubicin \\
\hline 0,781 & N/A & N/A & $38,2 \pm 0,47$ \\
1,562 & N/A & N/A & $50,8 \pm 0,42$ \\
3,125 & $2,4 \pm 6,20$ & $-9,6 \pm 1,50$ & $60,8 \pm 0,20$ \\
6,25 & $9,9 \pm 4,41$ & $17,9 \pm 1,34$ & $67,2 \pm 0,47$ \\
12,5 & $18,5 \pm 2,57$ & $39,1 \pm 0,82$ & $72,5 \pm 0,69$ \\
25 & $31,5 \pm 0,78$ & $48,9 \pm 2,01$ & $87,5 \pm 0,27$ \\
50 & $38,1 \pm 2,66$ & $61,5 \pm 1,29$ & N/A \\
100 & $55,7 \pm 2,05$ & $91,7 \pm 0,18$ & N/A \\
\hline
\end{tabular}

N/A: was not conducted in this study

Tabel 2: $I_{50}$ value of $n$-Hexane extract of $K$. pandurata Roxb. and nanoparticle of K. pandurata Roxb. $n$-Hexane extract and doxorubicin.

\begin{tabular}{ccccc}
\hline \multirow{2}{*}{ Sample } & \multicolumn{4}{c}{$\mathrm{IC}_{50}$ Value $(\mu \mathrm{g} / \mathrm{ml})$} \\
\cline { 2 - 5 } & Test 1 & Test 2 & Test 3 & Mean \pm S.D \\
\hline Extract & 79,88 & 89,94 & 93,12 & $87,23 \pm 6,91$ \\
Nanoparticle & 24,15 & 24,59 & 23,94 & $24,23 \pm 0,33$ \\
Doxorubicin & 1,65 & 1,66 & 1,67 & $1,66 \pm 0,01$ \\
\hline
\end{tabular}


IC50 values are calculated through the line equation from the log concentration graph ( $\mathrm{X}$ axis) to the percentage of inhibition ( $\mathrm{Y}$ axis). The log line equation for the concentration of $n$-hexane extract of $K$. pandurata Roxb. to percentage inhibition was $\mathrm{y}=34,594 \mathrm{x}-17,135$. The log line equation for the concentration of nanoparticle of $\mathrm{K}$. pandurata Roxb. $\mathrm{n}$-hexane extract to percentage inhibition was $\mathrm{y}=$ $61,383 x-34,978$. The log line equation for doxorubicin concentration to percentage inhibition is $y=30,174 x-43,362$. The $Y$ axis is the percentage of inhibition, while the $\mathrm{X}$ axis is the log of concentration. The $\mathrm{IC}_{50}$ value is the concentration when the percentage of inhibition is $50 \%$. This formula is used for all three samples (Table 2).

\section{DISCUSSION}

\section{Nanoparticle analysis}

Nanoparticles in this study were synthesized from the basic ingredients of chitosan and alginate by the ionic gelation method. The crosslinking agents in these nanoparticles are alginate and $\mathrm{CaCl}_{2}$. $\mathrm{n}$-Hexane extract of K. pandurata Roxb. is hydrophobic, while the outer portion of nanoparticles is hydrophilic. The mechanism of ionic gelation of compounds in nanoparticles is still unclear, but in principle nanoparticles are formed from the process of "wrapping" a calcium-alginate complex which is negatively charged in the pregelation phase with cationic polymers. This pre-gelation phase plays an important role in the ionic interactions between chitosan, alginate, and calcium. Comparison between chitosan: alginate: $\mathrm{CaCl}_{2}$ (50:250:50) is used to keep calcium-alginate in the pre-gelation phase and chitosan concentration as a cationic polymer is suitable in the process of forming nanoparticles. ${ }^{14}$

Research by Maity, et al. said that naringenin is one of flavonoids that have nonpolar properties like the major compounds in n-hexane extract of K. pandurata Roxb., pinostrobin and pinocembrin. ${ }^{15,16}$ The structure of the flavonoids in the chitosan-alginate nanoparticles as Figure 4. shows that naringenin is inside the nuclear envelope with the crosslinking of sulfate anions in chitosan. While alginate is outside the nucleus, forming a cloak with a cross bond to the calcium ion. ${ }^{15}$

UV / VIS spectrophotometry was used to calculate yield, in this study the yield of nanoparticle of K. pandurata Roxb. n-hexane extract was $99.43 \%$. Yield describes the concentrations of extracts that are captured in nanoparticles. There is no classification of nanoparticle characteristics based on yield, but in general in the synthesis of yield values above $75 \%$ declared successful.

The TEM test produces an image of nanoparticles are black on the outside and transparent on the inside. Polar compounds are in the black part, while nonpolar compounds are in the transparent part. n-Hexane extract of K. pandurata Roxb. is classified as nonpolar extract so that it occupies an area inside the nanoparticles. ${ }^{17}$

Analysis of cyotoxicity effect of K. pandurata Roxb. n-Heksana extract and nanoparticles towards MDA-MB-231 cell

IC50 value is the concentration value needed for a compound to inhibit $50 \%$ biological function or $50 \%$ growth (in this case cancer cells). The smaller IC50 value indicates strong anticancer properties. The IC50 value of key Intersection $n$-hexane extract was higher than the IC50 value of the nanoparticles, this showed that the cytotoxicity of the extract was weaker than the cytotoxicity of the nanoparticles.

Studies on the cytotoxicity test of K. pandurata Roxb n-hexane extract and nanoparticles were also carried out on ER + breast cancer cells. According to Edina BC (2018), IC $_{50}$ extracts of n-hexane key and nanoparticles were $94.37 \mu \mathrm{g} / \mathrm{ml}$ and $31.297 \mu \mathrm{g} / \mathrm{ml}$, respectively. This shows that cytotoxicity of K. pandurata Roxb. n-hexane extracts and nanoparticles is better to ER- cancer cells. Specific compounds that cause differences in strength in ER + and ER-cancer cells have not been established in this study. ${ }^{18}$

According to Ostad et al, the classification of anticancer activity based on $\mathrm{IC}_{50}$ values is: $\mathrm{IC}_{50}$ values $<10 \mu \mathrm{g} / \mathrm{ml}$ were classified as strong, $\mathrm{IC}_{50}$ $<100 \mu \mathrm{g} / \mathrm{ml}$ were moderate, and $\mathrm{IC}_{50} \geq 100$ were classified as weak or non-cytotoxic. ${ }^{14}$ Based on this classification, the anticancer activity of K. pandurata Roxb. n-hexane extract and its nanoparticles is classified as moderate. ${ }^{19}$

n-Hexane extract of K. pandurata Roxb. contains anticancer compounds from the flavonoid group such as pinostrobin, pinocembrin, and pinocembrin chalcone. Previous research has shown that compounds found in these key findings can interact with estrogen receptors and vascular endotheliate growth factor (VEGF). This can inhibit the growth of cancer cells. MDA-MB-231 breast cancer cells do not express estrogen receptors, but express VEGF receptors. ${ }^{20}$

The synthesis of nanoparticle of K. pandurata Roxb. n-hexane extract increases the cytotoxic effect of the extract on MDA-MB-231 cancer cells. Nanoparticle of K. pandurata Roxb. n-hexane extract have a better cytotoxic activity against MDA-MB-231 cells than its extract because of the favorable chitosan-alginate nanoparticle characteristics in the administration of compounds in $\mathrm{n}$-hexane extract of K.pandurata Roxb. ${ }^{17}$

Chitosan-alginate nanoparticles are safe because they are natural polymers. The outermost part of nanoparticles which are hydrophilic but can carry major compounds in the extract, namely pinostrobin and pinocembrin which are hydrophobic, will prolong the contact time between the substrate and cell membrane, and increase the uptake of anticancer compounds. The size of the nanoparticles also facilitates the compounds inside to pass through the cell membrane. Those characteristics increase the bioavailability of a compound so that nanoparticles are ideal as a drug career. ${ }^{17-20}$

The MDA-MB-231 cell is used as an example of ER- because it is one of the ER- and TNBC group that tends to be malignant, has a poor prognosis, and resistant to some drugs. The percentage of breast cancer sufferers in Indonesia for the basal type (including MDA-MB-231 cells) is $37.4 \%$, higher than the percentage in the world which is $15 \%{ }^{21}$

Previous studies by Fadilah et al. (2018) who conducted an in vitro test with MTT assay of K. pandurata Roxb. extract on MDA-MB-231 breast cancer cells gives the $\mathrm{IC}_{50}$ results of $\mathrm{n}$-hexane extract by $20.54 \mu \mathrm{g}$ $/ \mathrm{ml}$ and ethyl acetate extract by $70.32 \mu \mathrm{g} / \mathrm{ml} .{ }^{15}$ However, there are no studies that synthesize and test the cytotoxicity of K. pandurata Roxb. nanoparticles. In addition to using the in vitro test, Fadilah $\mathrm{F}$ et al. also conducted in silico tests based on bioinformatics with molecular docking and molecular dynamic methods. The results of the in silico test showed that the pinostrobin and pinocembrin compounds from the K. pandurata Roxb. could interact with estrogen and VEGF receptors so that they could be used as anticancer drugs for ER + and ER- breast cancer cells. $^{20}$

\section{CONCLUSION}

Nanoparticle of K. pandurata Roxb. hexane extract can be synthesized using chitosan and alginate as the basis with ionic gelation method. n-Hexane extract of K. pandurata Roxb. with $\mathrm{IC}_{50}$ value of $87.23 \mu \mathrm{g} / \mathrm{ml}$ has a moderate cytotoxic effect on MDA-MB-231 breast cancer cells. Nanoparticle of K. pandurata Roxb. n-hexane extract with IC50 values of $24.23 \mu \mathrm{g} / \mathrm{ml}$ have moderate cytotoxic effects on MDA-MB-231 breast cancer cells. The nanoparticles have a higher cytotoxicity against MDA-MB-231 breast cancer cells than the extract. 


\section{ACKNOWLEDGMENTS}

The authors are thankful to team research of Bioinformatics Core facilities, Biobank Research FKUI-RSCM, Cluster of Drug Development IMERI FKUI and Universitas Indonesia (UI), for supported by a research Grant from PITTA 2019

\section{REFERENCES}

1. GLOBOCAN 2018. Estimated number of cases worldwide, both sexes, all ages [Internet]. France: International Agency for Research on Cancer; 2018 [cited 2019 Jul 15]. Available from: bit.ly/CancerTodayGLOBOCAN2018

2. GLOBOCAN 2018. Indonesia fact sheets. France: The Global Cancer Observatory. 2019;1-2.

3. Lumachi F, Santeufemia DA, Basso SMM. Current medical treatment of estrogen receptor-positive breast cancer. World J Biol Chem. 2015;6(3):231-9.

4. Chabner BA, Roberts TG. Timeline: chemotherapy and the war on cancer. Nat Rev Cancer. 2005;5:65-72.

5. Chavez KJ, Garimella SV, Lipkowitz S. Triple negative breast cancer cell lines: one tool in the search for better treatment of triple negative breast cancer. Breast Dis. 2010;32(1-2):35-48.
6. Perrot-Applanat $M$, Benedetto MD. Autocrine functions of VEGF in breast tumor cells. Cell Adh Migr. 2012;6(6):547-53.

7. Chumsri S, Howes T, Bao T, Sabnis G, Brodie A. Aromatase, aromatase inhibitors, and breast cancer. J Steroid Biochem Mol Biol. 2011;125(1-2):13-22.

8. Chahyadi A, Hartati R, Wirasutisna KR, Elfahmi. Boesenbergia pandurata Roxb., an Indonesian medicinal plant: Phytochemistry, biological activity, plant biotechnology. Procedia Chemistry. 2014;(13):13-37.

9. Taweechaisupapong $S$, Singhara $S$, Lertsatitthanakorn $P$, Khunkitti W Antimicrobial effects of Boesenbergia pandurata and Piper sarmentosum leaf extracts on planktonic cells and biofilm of oral pathogens. J Pharm Sci. 2010;23:224-31.

10. Nurrachma MY, Fadliyah $H$, Meiyanto E. Fingerroot (Boesenbergia pandurata): A prospective anticancer therapy. Indones J Cancer Chmoprevent. 2018;9(2):102-9.

11. Rizvi SAA, Saleh AM. Applications of nanoparticle systems in drug delivery technology. Saudi Pharm J. 2018;26(1):64-70.

12. Meng X, Zhang H, Mezei M, Cui M. Molecular docking: A powerful approach for structure-based drug discovery. Curr Comput Aided Drug Des. 2011;7(2):146-57

13. Introduction of ultraviolet-visible spectroscopy. London: Royal Society of Chemistry; 2009;1-7.

14. Li P, Dai Y, Zhang J, Wang A, Wei Q. Chitosan-alginate nanoparticles as a novel drug delivery system for nifedipine. Int J Biomed Sci. 2008;4(3):221-8.

\section{GRAPHICAL ABSTRACT}

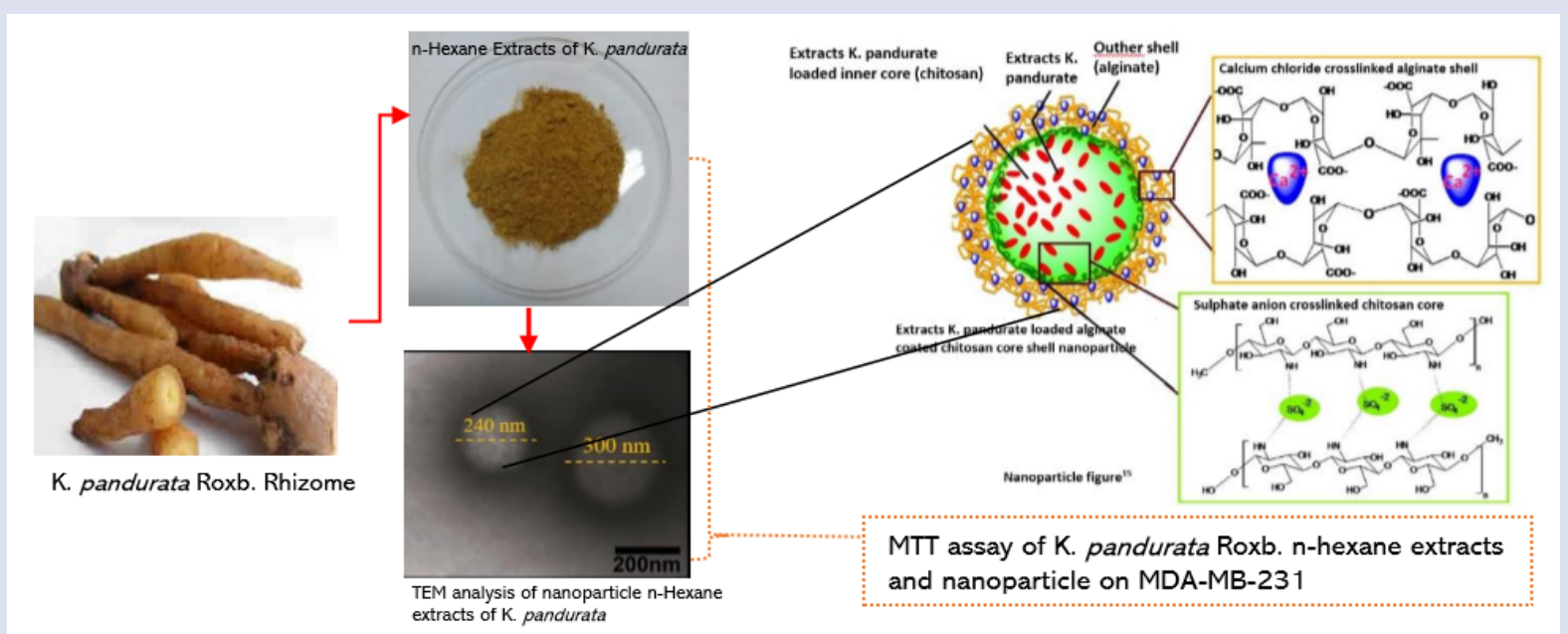

\section{SUMMARY}

Nanoparticle is a form of preparation that optimizes the activity of any compound to the targeted cell. Therefore, it is expected that it can increase the effectivity of anticancer by MTT assay on cell line from extracts of Kaempferia pandurata Roxb. In this study, rhizome of $K$. pandurata Roxb. as anticancer activity on MDA-MB-231 breast cancer cell line of n-hexane extract and nanoparticle of $K$. pandurata Roxb. is moderate with $I C_{50}$ value of the extract is $87,23 \mu \mathrm{g} / \mathrm{ml}$ and the nanoparticle is $24,23 \mu \mathrm{g} / \mathrm{ml}$.

\section{ABOUT AUTHORS}

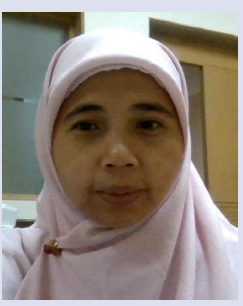

Fadilah Fadilah obtained his doctor's degree from the pharmaceutical chemistry, Faculty of pharmacy Universitas Indonesia. She has lecturer and researcher in Drug Development Research Center - IMERI, Bioinformatics Core Facilities - IMERI, Medical Chemistry Departement, Faculty of Medicine Universitas Indonesia, She has author and co author 22 publications including drug discovery from herbal medicine, structure activity relationship analysis, molecular modelling, design and screening of active compounds derivatives. Her current research focuses an using computational simulation of drug development based on gene mutation, analysis of next generation sequencing based on database.

\section{Risya Amelia Rahmawanti}

Undergraduate Medical Program, Faculty of Medicine Universitas Indonesia, Jalan Salemba Raya No.6, Jakarta Pusat, 10430, Indonesia. 


\section{Brenda Cristie Edina}

Undergraduate Medical Program, Faculty of Medicine Universitas Indonesia, Salemba Raya No.6, Jakarta Pusat, 10430, Indonesia.

\section{Lowilius Wiyono}

Undergraduate Medical Program, Faculty of Medicine Universitas Indonesia, Salemba Raya No.6, Jakarta Pusat, 10430, Indonesia.

\section{Rafika Indah Paramita}

She has lecturer and researcher in Drug Development Research Center - IMERI, Bioinformatics Core Facilities - IMERI, Medical Chemistry Departement, Faculty of Medicine Universitas Indonesia. Salemba Raya street number 6, Jakarta, Indonesia - 10430.

Cite this article: Rahmawanti RA, Fadilah F, Edina BC, Wiyono L, Paramita RI. Nanoparticle Synthesis and Cytotoxicity of Kaempferia pandurata Roxb. Extract to the Growth of MDA-MB-231 Breast Cancer Cell Line. Pharmacog J. 2020;12(1):109-14. 